\title{
HIPOPLASIA DE ESMALTE EM PACIENTE COM ANEMIA FALCIFORME - RELATO DE CASO
}

Danielle Del SANTO, Giovana GABARDO, Milena ALBINI, Norma Suely Falcão de Oliveira MELO, Antônio Adilson Soares de LIMA

Doença falciforme é uma hemoglobinopatia hereditária caracterizada por eritrócito em forma elíptica em vez de oval. Os sinais e sintomas clínicos são episódios de dor aguda, comprometimento pulmonar, danos generalizados nos órgãos e aumento do risco de óbito. O diagnóstico deste tipo de anemia deve idealmente ser realizado antes do surgimento da sintomatologia clínica e de suas complicações. Por ser uma condição multissistêmica, afeta também a cavidade bucal, apesar de poucos estudos terem sido feitos sobre as possíveis conseqüências da doença sobre os tecidos bucais de indivíduos falcêmicos. $O$ presente relato de caso trata de uma criança com anemia falciforme em atendimento na Clínica de Hematologia do Departamento de Pediatria da UFPR. Paciente do sexo feminino, 11 anos de idade, raça branca, em dentição mista e em tratamento de doença falciforme. O exame clínico intra-oral mostrou que os dentes apresentavam alterações na estrutura dental, sendo estabelecido o diagnóstico de hipoplasia de esmalte. O esmalte dental apresentava manhas brancas em toda a sua extensão, o que leva a um prejuízo da estética. As crianças com anemia falciforme devem ser avaliadas por um cirurgião-dentista afim de que sejam diagnosticadas alterações que possam comprometer o estado de saúde bucal e geral dos pacientes.

Palavras chaves: anemia falciforme; anormalidades dentárias; manchas brancas 